\title{
Modelling the Seismic Out-of-plane Behaviour of Rammed Earth Components
}

\author{
Reza Allahvirdizadeh, Daniel V. Oliveira, Rui A. Silva \\ ISISE, Department of Civil Engineering, University of Minho, Guimarães, Portugal
}

Contact: allahvirdizadeh@gmail.com; danvco@civil.uminho.pt; ruisilva@civil.uminho.pt

\begin{abstract}
Earthen constructions constitute a considerable part of the existing heritage and a large percentage of the World population is still living or working in buildings built with this structural material. Rammed earth constructions are acceptably stable under gravity loads, but are significantly vulnerable to earthquakes. Strengthening methods used to enhance the load capacity and ductility of the building should also satisfy a variety of principles, such as compatibility with the substrate, affordability and reversibility. In this study, the seismic performance of both unstrengthened and strengthened rammed earth structural components is investigated. In particular, the out-of-plane behaviour is studied by means of different nonlinear finite element models. At first, pushover analysis is conducted on unstrengthened walls to evaluate their capacity and understand possible failure mechanisms. Afterwards, pushover analyses are conducted on strengthened walls to choose between different strengthening materials and assess the effectiveness of the adopted strengthening technique. Finally, an artificially generated ground motion record is applied to both unstrengthened and strengthened structural components to perform nonlinear time-history analyses. The outcomes were used to compare the dynamic behaviour of the structure against the results of the pushover analyses.
\end{abstract}

Keywords: Rammed earth; Modelling; Seismic behaviour; Strengthening

\section{Introduction}

Raw earth is one of the most available building materials used since ancient times in many regions. Hence, different techniques have been developed using it, among which adobe, brick and rammed earth are the most widespread. The extensive use of these techniques resulted in the construction of a relevant percentage of the World heritage sites and of the built stock.

In general, earthen structures easily withstand gravity loads, but deficiencies such as low tensile strength and weak connections make them significantly vulnerable to earthquakes. In this regard, many catastrophic failures in rural regions and historical sites are reported, e.g. in Turkey (Erzinkan 1992), Iran (Bam 2003), Peru (Pisco 2007) and Chile (Concepción 2010).

Recent decades witnessed the substitution of earthen materials by modern ones. Nevertheless the necessity of preserving historical monuments and also their green construction nature (which makes them a possible option for future construction) attracted great attention. Hence, the current study is particularly focused on the seismic out-of-plane performance of rammed earth components on both plain and strengthened cases. In rammed earth construction moist earth is placed within a formwork and then is rammed to obtain a compact section (see Figure 1). 

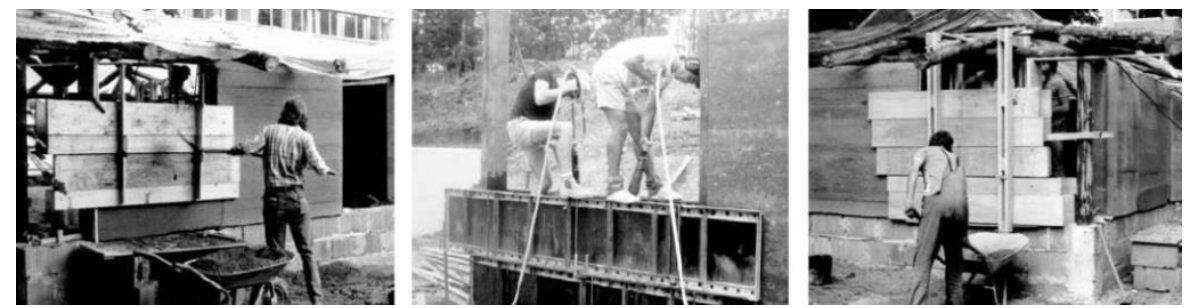

Figure 1. Rammed earth construction process [1]

Composite-based low-cost textile reinforced mortar (LC-TRM) was adopted as the strengthening solution and its effectiveness to improve the seismic response of the rammed earth components was evaluated. It should be noted that compositebased strengthening solutions, especially FRPs are widely used to enhance the in-plane and out-ofplane response of masonry, increase their stiffness/strength, confine column/piers and repair existing cracks. Though, reversibility issues, lack of vapour permeability and poor high temperature resistance of FRPs encouraged researchers to seek novel solutions [2]. Most of aforementioned issues are due to use of organic epoxy resins, which in solutions like LC-TRM are replaced by more compatible matrixes like cement-, lime- or earthbased mortars. The procedure of applying TRM strengthening is shown in Figure 2.
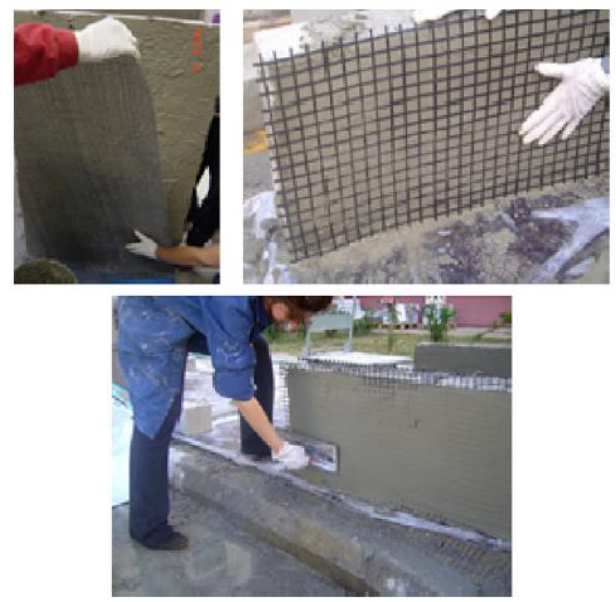

Figure 2.Procedure of applying TRM [3]

\section{Nonlinear finite element modelling}

This study aims to numerically investigate the seismic out-of-plane response of rammed earth components. Hence, this section describes the geometry, material properties and modelling assumptions adopted.

\subsection{Geometry of the model}

Shaking table tests will be carried out in a near future within the framework of the project SafEarth. Though, the high cost of such tests demands performing preliminary numerical studies to predict the capacity and failure mechanisms, which can then be used to adjust the testing program with the objective of observing the expected phenomena. Furthermore, the considered numerical models should be compatible with the testing conditions and that of the practice. In this regard, outcomes of surveying different rammed earth buildings from Alentejo region (southern Portugal) were taken into account to define the geometry of the model [4]. It was noticed that the wall thickness in all cases was of about $0.5 \mathrm{~m}$ and the average length and height were $3.52 \mathrm{~m}$ and 2.19 , respectively. Therefore, the considered geometry and corresponding dimensions are as shown in Figure 3. Furthermore, it should be mentioned that the shaking table is capable to test mockups with maximum mass of 21 tons [5]. Considering the density of rammed earth found in Alentejo region as $2000 \mathrm{~kg} / \mathrm{m}^{3}$ [6], the mass of the model would be about 18 tons.

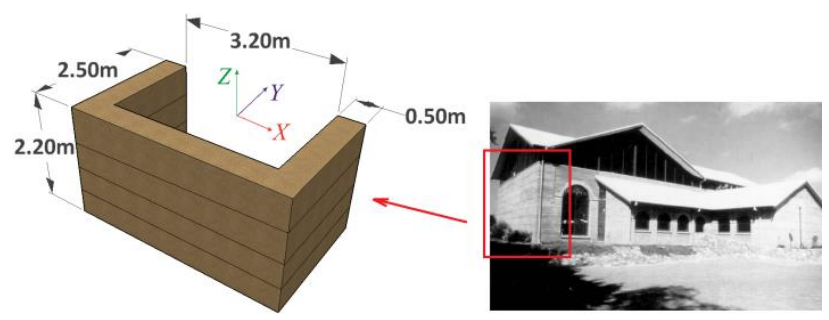

Figure 3. Geometry of the out-of-plane model (photo of Margaret River church in Australia [1])

\subsection{Material properties}

Defining nonlinear finite element models representing the behaviour of both plain and LC- 
TRM strengthened walls requires assigning proper material models to substrate, composite strengthening (mortar and textile) and also to interfaces substrate-matrix and matrix-fibres. The material properties used for rammed earth and LC-TRM are obtained from previous experiments, however the bond behaviour for this type of structures is practically absent from literature.

\subsubsection{Rammed earth}

Rammed earth presents an acceptable behaviour under compression stresses; however a low tensile strength should be expected. In this respect, previous experimental studies have highlighted its considerable nonlinear behaviour, which initiates at very low stress levels [6].

Moreover, comparing obtained outcomes from recent numerical investigations with those corresponding to experimental responses showed that using conventional parabolic stress-strain relationship would be less efficient than assigning a multi-linear behaviour [7-8]. Hence, an identical approach is followed in this study by averaging results of the compression tests on cylindrical rammed earth specimens, detailed in Figure 4 . It is worthwhile to note that due to lack of reliable data in post-peak behaviour, a fictitious descending branch with the same slope of the experimental curve is assumed. This part is shown with dash-line in Figure 4.

Additionally, an exponential softening relationship based on fracture energy is considered for the tensile behaviour.

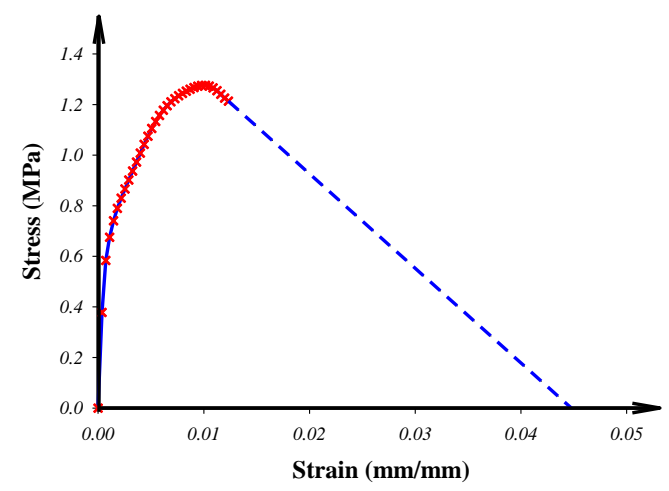

Figure 4. Adopted multi-linear stress-strain behaviour of rammed earth in compression

\subsubsection{LC-TRM strengthening}

The adopted LC-TRM strengthening solution consisted of an earth-based mortar reinforced with a glass fibre mesh, which was previously proposed in [9]. Although, the accurate modelling of the strengthening solution requires precise consideration of mortar, textile and also their bond, only the experimental characterisation of the composite behaviour is available from past research.

The current study considered the adopted strengthening as a homogenous material and its behaviour is derived from uniaxial tensile and compression tests. In tension, the behaviour is defined by averaging experimental curves and by proposing a trilinear equivalent behaviour. It is evident that such approach prevents simulating any possible slippage of mesh within mortar; nevertheless it provides valuable information on general response of the wall.

On the other hand, contribution of the textile is neglected in definition of the compressive behaviour, meaning that the compression behaviour can be assumed as that of the mortar alone. Thus, the average stress-strain curve obtained from the tests presented in [10] were used to define the multi-linear relationship used to simulate the compression behaviour of the LCTRM. Here, the softening behaviour was defined in a similar way to that of rammed earth (see [11] for further details). Finally, the adopted stressstrain relationship of the LC-TRM strengthening is presented in Figure 5.

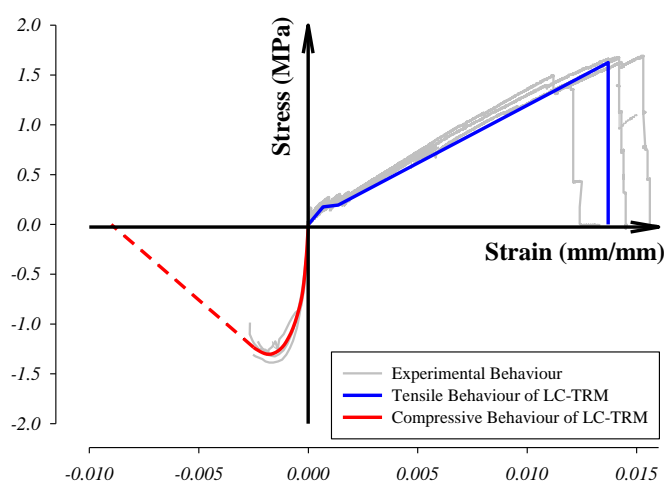

Figure 5. Adopted behaviour of the LC-TRM 


\subsection{Modelling considerations}

Masonry structures are commonly modelled using shell or solid elements, though in the case of rammed earth the thickness is relevant with respect to the other dimensions. Therefore, nonnegligible errors would be expected in rammed earth models constructed with shell elements (see [11]), meaning that solid elements were adopted for the preparation of the out-of-plane model.

In this regard, 20 nodes iso-parametric brick elements, denoted as CHX60 in DIANA FEA [12] software, were used. Additionally, the strengthening is modelled using 8 node quadrilateral curved shell elements (CQ40S). It is worthwhile to note that the bond (interface) between strengthening and the substrate (wall) is assumed as being perfect.

\subsection{Pushover analyses}

In this section nonlinear static analyses (so-called pushover) are performed to assess the out-ofplane seismic performance of the models. It is widely discussed in the literature that pushover analyses have less reliability in comparison with dynamic analyses, particularly regarding damage simulation. However, their outcomes well agree with the average of real responses [13]. Therefore, pushover analyses are widely used to obtain a general idea about seismic capacity and possible failure mechanisms.

In this section, mass-proportional pushover analyses are performed on the considered models. However, due to asymmetric geometry of the rammed earth component, the results are presented both for the positive and negative (pushed toward and outside of the wing walls, respectively) directions. The capacity curve of the unstrengthened model is shown in Figure 6.

As it was expected, the model has less capacity when pushed in negative direction, since transverse walls do not resist against rotation of extreme sides of the web. In this regard, $60.1 \%$ and $48.6 \%$ difference can be observed between peak strength and displacement capacities, respectively.

Moreover, the damage initiation point (the point in which cracks open) is also depicted in Figure 6.
As it is evident, it happens at very low lateral load levels, as a consequence of the highly nonlinear behaviour of rammed earth.

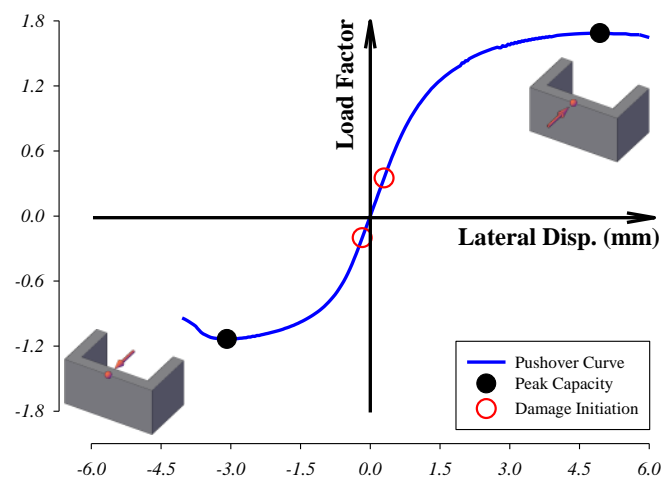

Figure 6. Capacity curve of the plain model

Additionally, detailed investigation of occurred failure modes can be achieved by studying the contour map of the principal tensile strains $\left(\varepsilon_{1}\right)$ at a lateral load equal to the peak capacity of the wall. Outcomes for the both pushing directions are shown in Figure 7.

As it can be seen, a large mid-section of the web wall tends to rotate when the model is pushed in positive direction. Moreover, high strains at the base evidence that probably the whole wall is likely to overturn. On the other hand, the highest strains in the model pushed in the negative direction are localized in the connection of web and wing walls. It highlights the tendency of web to detach from the wings. The same conclusion can be derived from the strain at in the base. As it is clear, each three parts of the model are likely to overturn individually, which can be interpreted as possible loss of integrity.

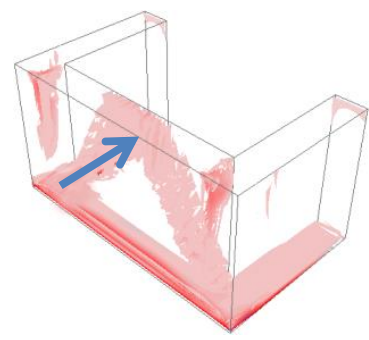

(a) Positive direction

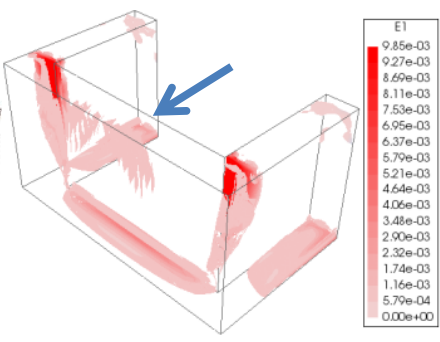

(b) Negative direction
Figure 7. Principal tensile strains $\left(\varepsilon_{1}\right)$ of the plain model at its peak capacity 
Similar analyses were also conducted on the strengthened model to evaluate its efficiency on promoting the seismic out-of-plane performance of the rammed earth components. The capacity curve of the strengthened model pushed in both directions is compared with that of the plain model in Figure 8.

It can be seen that the strengthening has slightly increased the stiffness of the model, but the damage initiation points are similar in both models. Moreover, the strengthening improved the lateral displacement and strength capacities when the model is pushed in the positive direction, namely of about $131 \%$ and $30.5 \%$, respectively. The improvement of the strengthened model pushed in negative direction was of about $45 \%$ and $28.5 \%$, respectively for lateral displacement and load capacities. Additionally, it can be noticed that the strengthening results in smoother post-peak behaviour.

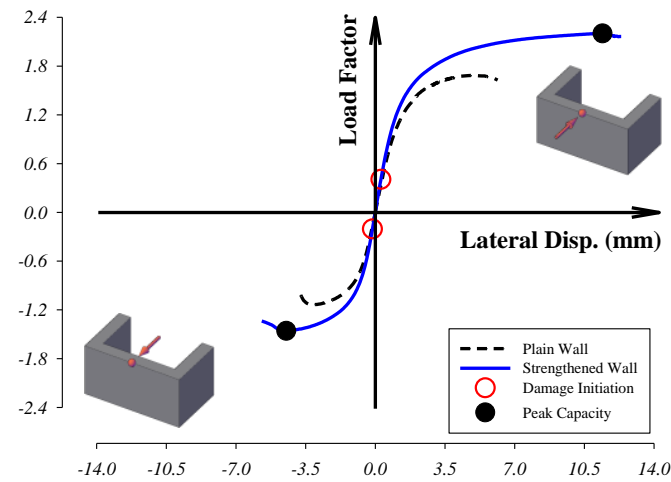

Figure 8. Capacity curve of the strengthened model

The, contour map of the principal tensile strains was also investigated to evaluate the influence of strengthening on the failure mechanisms. It should be noted that since pushing in negative direction is more severe, the results are presented only for this case (see Figure 9). It is worthwhile to note that Figure $9 a$ and $b$ present the principal tensile strains of the strengthened wall at a lateral load levels equal to the peak capacity of the plain and strengthened walls, respectively, however Figure $9 c$ shows principal tensile strains of the LCTRM (applied strengthening) at the peak capacity state of the strengthened model.
A considerable reduction in principal tensile strains can be observed in the strengthened model at a lateral load equal to the peak capacity of the plain wall (see Figure 9a in comparison to Figure 7b). As it can be seen, the detachment of the wings is prevented. On the other hand, the strain state in the strengthened model at its peak capacity shows that the strengthening does not change the failure mechanism (see Figure 9b). However, a larger mid-section tends to rotate or detach from the wing walls, which consequently means that a higher load causes the failure. Moreover, comparing the strains at the base of the strengthened model with that of the plain one reveals that the wall integrity loss is mitigated. In other words, instead of overturning of the three individual walls, the whole model tends to overturn.

Finally, for an efficient strengthening solution, it is important to identify the regions expected to fail, which can be evaluated by investigating principal tensile strains of the strengthening (see Figure 9c). As it is evident, the highest strains occur in the connection between the web and the wing wall.

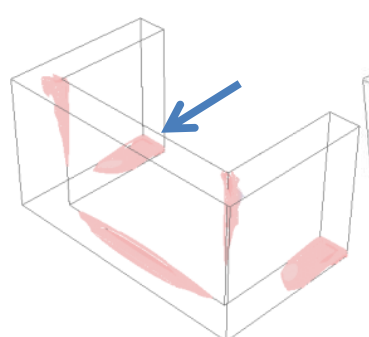

(a) Strengthened model at peak capacity of plain one

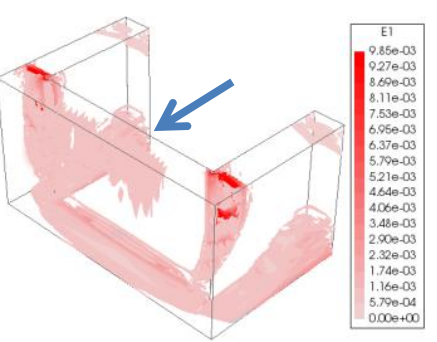

(b) Strengthened model at its peak capacity

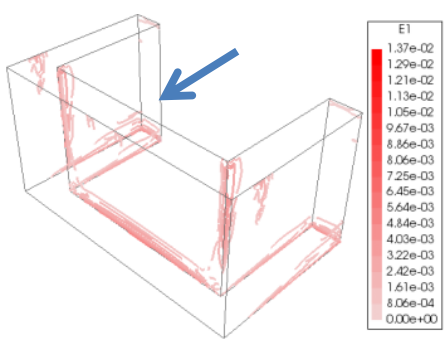

(c) TRM strengthening at peak capacity of strengthened model

Figure 9. Principal tensile strains $\left(\varepsilon_{1}\right)$ of the strengthened model 


\subsection{Time-history analysis}

This section evaluates the seismic response of both plain and strengthened models by means of nonlinear time-history analyses. In this regard, it is essential to induce a proper ground motion record, which can be selected from previous event or generated synthetically from seismological models and fault dimensions. On the other hand, selection procedures are categorized into two general groups, i.e. selection based on magnitude (M) or source to recording station distance (R) and selection based on uniform hazard spectrum (UHS) or conditional mean spectrum (CMS) [14].

In this study, an artificially generated ground motion record was applied to the model. In this regard, the near-field earthquake design spectrum from Odemira (Alentejo region) was taken into account (see Figure 10).

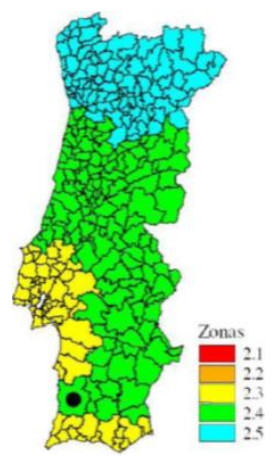

Figure 10. Portuguese seismic hazard map for earthquakes with 475 years returning period for a near-field scenario (type 2) [15]

The corresponding design spectrum, backbone of the artificial ground motion record and three modes of the plain model with highest contribution are shown in Figure 11. As it is evident, all modes are in the first branch of the spectrum, which means that the model would be sensitive to high frequency earthquakes.

Afterwards, Simqke-gr software, developed at University of Brescia was employed to generate a compatible ground motion record and subsequently SeismoSignal software [16] was used to perform baseline correction by filtering frequencies outside of the [0.1-20.0] $\mathrm{Hz}$ range. Finally, the applied ground motion record is as presented in Figure 12.

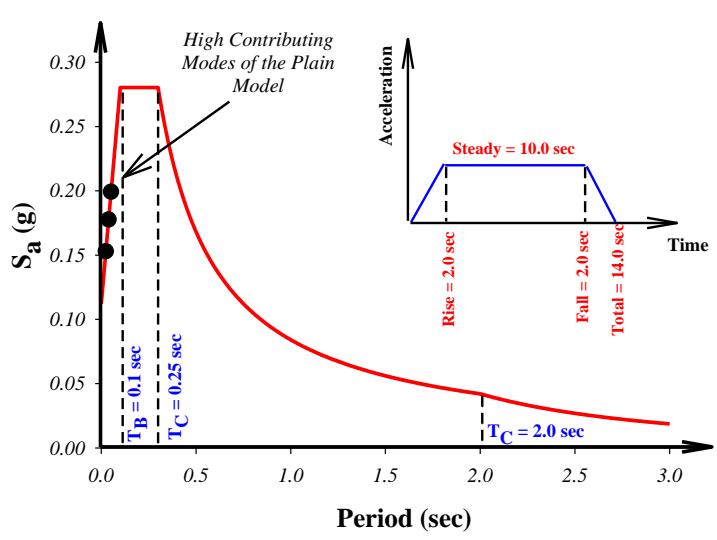

Figure 11. Design spectrum for near-field ground motions and schematic backbone of the artificially generated records

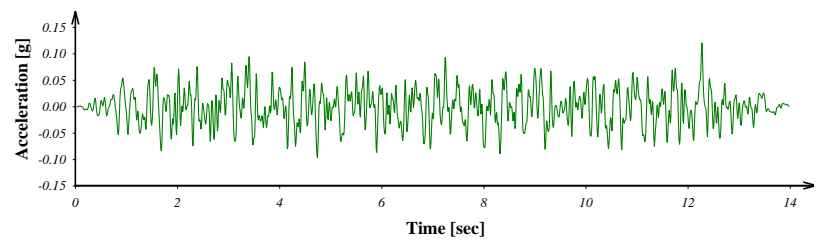

Figure 12. Artificially generated ground motion record

Another key parameter in dynamic analyses is the damping ratio. It should be noted that there is no general consensus regarding the damping ratio of rammed earth buildings, but applying Half-Power Band Width method on outcomes of a set of insitu dynamic measurements resulted their damping ratio to be in range of $2.5-4.0 \%$ [16]. Therefore, a Rayleigh damping with 3\% viscous damping was assigned to the model. Moreover, the intensity of the earthquake was increased in subsequent dynamic analyses in order to compare the outcomes with those resulted from the pushover analyses. This procedure required scaling the adopted ground motion, though it should be noted that as it is widely discussed in the literature, the obtained outcomes may drastically vary based on the employed scaling method [18]. This concept is beyond the scope of the current study, hence conventional linear scaling is used. In this regard, three scale factors, i.e. 1.0, 5.0 and 9.0 were taken into account.

Figure 13 exemplifies hysteretic curve obtained from the dynamic analyses, namely for the earthquake with scale factor of 5.0. Comparing the derived results (envelope of the hysteretic curves) for both plain and strengthened models 
(presented in Figure 14) clears that the applied strengthening considerably decreases the experienced lateral displacements, however no major demand variation is observed (since applied strengthening do not significantly induce additional mass). Moreover, the area of hysteretic envelope represents the amount of dissipated energy by the model, where larger area denotes higher dissipated energy. Therefore, it can be concluded that the adopted strengthening solution significantly enhances this dynamic behavior, in particular the energy dissipation of the wall.

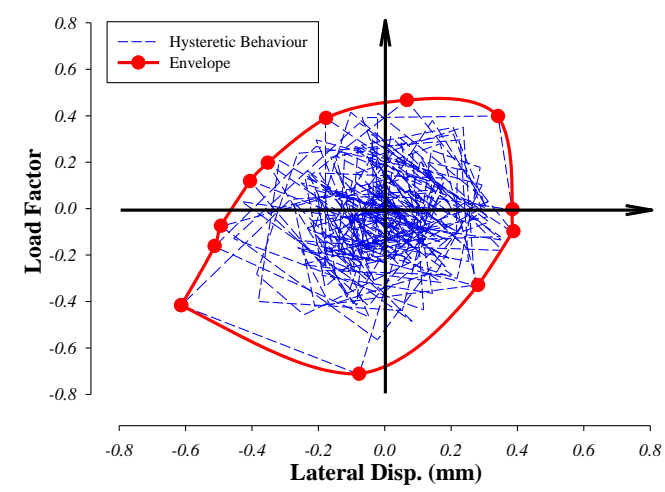

Figure 13. Hysteretic curve for strengthened model subjected to the earthquake with scale factor of 5.0

Finally, the responses of time-history analyses are compared with those obtained from the pushover analyses (see Figure 14). As it is clear, the plain model seems to sway in much less load factors predicted by pushover analysis. In other words, the pushover analysis overestimates the capacity. Same diversity in outcomes may be observed for the strengthened model also. On the other hand, considerable reduction in the experienced lateral displacement in the strengthened model is evident. It should be noted that there is no relevant knowledge on cyclic behavior and degradation rules of rammed earth; hence the outcomes are obtained using default values.

\section{Conclusions}

This study assessed the seismic out-of-plane response of a rammed earth component and evaluated the efficiency of adopted LC-TRM strengthening. In this regard, the main remarks are listed as follows:

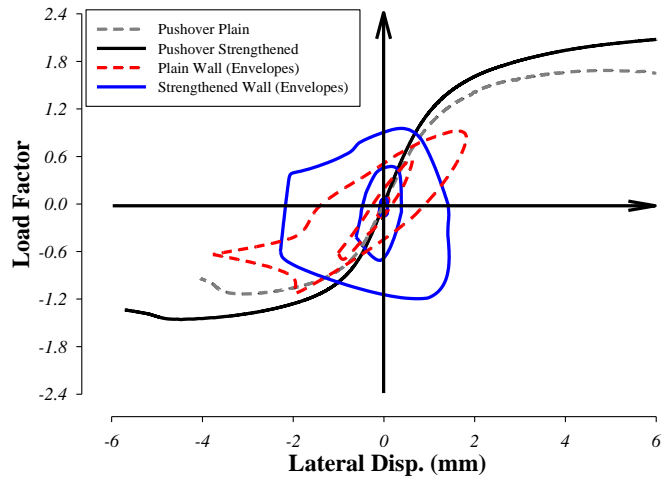

Figure 14. Envelope of hysteretic curves obtained for different scaling factors

- Pushing the model towards outside the transverse walls represents a more critical behaviour with respect to strength and lateral displacement capacities. Moreover, the post-peak response is more fragile.

- The possible failure mode of the plain model contains detachment of web from wings, bending of its mid-span section and overturning of each three individual walls.

- LC-TRM strengthening increased the lateral displacement and load capacities of the model in about $45 \%$ and $28.5 \%$, respectively. These values represent the observed improvement in the critical direction.

- The strengthening does not change the failure mode; however it fully prevents its occurrence at a lateral load level equal to peak capacity of the plain model. Moreover, a larger section tends to detach or bend at a lateral load equal to the peak capacity of the strengthened wall, which clears its greater strength. The strengthening also promotes a smoother post-peak and preservation of the integrity of the model.

- The comparison of the outcomes from incremental dynamic analyses with those from the pushover analyses shows that the latter overestimates capacities and also the post-damage stiffness of the model.

\section{Acknowledgements}

This work was partly financed by FEDER funds through the Competitively Factors Operational Programme - COMPETE and by national funds through FCT - Foundation for Science and Technology within the scope of projects POCl-01- 
0145-FEDER-007633 and POCI-01-0145-FEDER016737 (PTDC/ECM-EST/2777/2014). The support from grant SFRH/BPD/97082/2013 is also acknowledged.

\section{References}

[1] Minke G. Building with Earth-Design and Technology of a Sustainable Architecture. Birkhãuser - Publisher for Architecture; 2006.

[2] Valluzzi M.R., Modena C., de Felice G. Current Practice and Open Issues in Strengthening Historical Buildings with Composites. Materials and Structures. 2014; 47(12): 1971-85.

[3] Papanicolaou C., Triantafillou T., Lekka M. Externally Bonded Grids as Strengthening and Seismic Retrofitting Materials of Masonry Panels. Construction and Building Materials. 2011; 25: 504-514.

[4] Correia M.R., Rammed Earth in Alentejo. ARGUMENTUM, Lisbon, Portugal; 2007.

[5] Mendes N. Seismic Assessment of Ancient Masonry Buildings: Shaking Table Tests and Numerical Analysis. PhD Dissertation. Guimarães, Portugal: University of Minho; 2012.

[6] Silva R.A. Repair of Earth Constructions by Means of Grout Injection. PhD Dissertation. Guimarães, Portugal: University of Minho; 2013.

[7] Miccoli L., Oliveira D.V., Silva R.A., Müller U., Schueremans L. Static Behaviour of Rammed Earth: Experimental Testing and Finite Element Modelling. Materials and Structures. 2015; 48(10): 3443-56.

[8] Librici C. Modeling of the Seismic Performance of a Rammed Earth Building. Master Thesis. Guimarães, Portugal: University of Minho; 2016.

[9] Barroso C.A. Reforço Sismico Inovador de Construção de Taipa, Master Thesis. Guimarães, Portugal: University of Minho; 2017.
[10] Oliveira D.V., Silva R.A., Barroso C., Lourenco P.B. Characterization of a Compatible Low Cost Strengthening Solution Based on the TRM Technique for Rammed Earth. Key Engineering Materials. 2017; 747: 150-157.

[11] Allahvirdizadeh R. Modelling of the Seismic Behaviour of TRM-Strengthened Rammed Earth Walls, Master Thesis. Guimarães, Portugal: University of Minho; 2017.

[12] DIANA FEA BV, Displacement Method ANAlyser, Release 10.1. Netherlands; 2017.

[13] Allahvirdizadeh R., Gholipour Y. Reliability Evaluation of Predicted Structural Performances Using Nonlinear Static Analysis. Bulletin of Earthquake Engineering. 2017; 15(5): 2129-48.

[14] Haselton C.B. et al. Evaluation of Ground Motion Selecting and Modification Methods: Predicting Median Inter-story Drift Response of Buildings. Chico, USA: Department of Civil Engineering, California State University; 2009.

[15] Norma Portuguesa, Eurocódigo 8: Projecto de estruturas para Resistência aos sismo Parte 1: Regras geris, acções sismicas $e$ regras para edificios. NP EN 1998-1; 2009.

[16] Seismosoft, SeismoSignal - A Computer Program for Signal Processing of TimeHistories; 2016. Available from URL: www.seismosoft.com.

[17] Bui Q.B., Hans S., Morel J.C. First Exploratory Study on Dynamic Characteristics of Rammed Earth Buildings. Engineering Structures. 2011; 33: 3690-95.

[18] Allahvirdizadeh R., Khanmohammadi M., Marefat M.S. Investigating Effects of Scaling and Selecting Earthquake Ground Motions on Performance-Based Design of $R C$ Buildings. $4^{\text {th }}$ International Conference on Concrete \& Development. Tehran, Iran; 2013. 